Abstracted/indexed in Academic Search Complete, Asia Journals Online, Bangladesh Journals Online, Biological Abstracts, BIOSIS Previews, CAB Abstracts, Current Abstracts, Directory of Open Access Journals, EMBASE/Excerpta Medica, Google Scholar, HINARI (WHO), International Pharmaceutical Abstracts, Open J-gate, Science Citation Index Expanded, SCOPUS and Social Sciences Citation Index;

\title{
A review on antidepressant effect of medicinal plants
}

\section{Zahra Rabiei ${ }^{1}$ and Sana Rabiei ${ }^{2}$}

${ }^{1}$ Medical Plants Research Center, Faculty of Medicine, Shahrekord University of Medical Sciences, Shahrekord, Iran; ${ }^{2}$ Department of Fisheries, Faculty of Marine Sciences, Tarbiat Modares University, Noor, Iran.

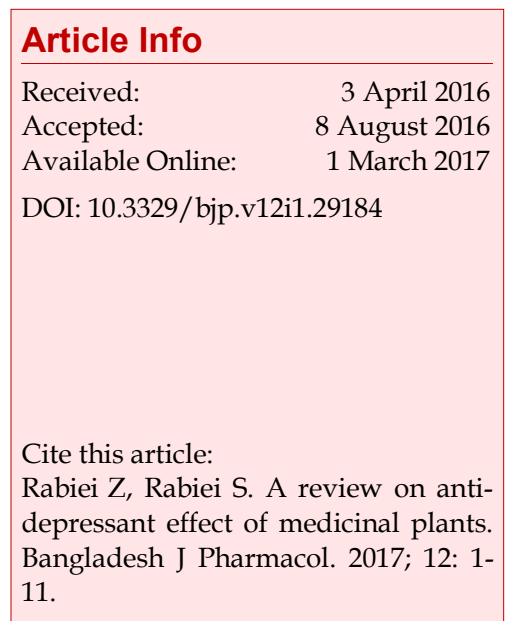

\begin{abstract}
Depression is a life-threatening, debilitating, and common disease affecting different segments of community. Chemical and synthetic drugs available to treat this disease cause many adverse effects and may lead to complete recovery in only $50 \%$ of patients. At the same time, medicinal plants have been reported to exert optimal pharmacological effects in treating depression in different models. In this review, the relevant articles indexed in the reliable databases PubMed, PubMed central, Scopus and Web of Science were reviewed. The review indicated that most medicinal plants exerted antidepressant effects through synaptic regulation of serotonin, noradrenaline, and dopamine, regulating activity of hypothalamic-pituitary-adrenal axis, reinforcing anti-oxidant defense system, and decreasing inflammatory mediators. The medicinal plants and their active compounds can relieve depression through different pathways and hence are considered a new source to produce antidepressants.
\end{abstract}

\section{Introduction}

Depression is a multifactorial, chronic, and life-threatening disease with globally high prevalence. Currently, $29 \%$ of the world population suffer from depression, considered to be one of the 10 leading causes of death (Menken et al., 2000; Grundmann et al., 2010; Singer et al., 2011; Cassani et al., 2015) According to the World Health Organization, depression will be the second leading disease in the developed countries in 2020 (Abbasi et al., 2013).

Depression affects not only the patients but also their friends and families. Social withdrawal, lack of motivation, sexual dysfunction, sleep disorders (in 75\% of the patients), nightmares, depressed mood, and anhedonia are the main symptoms of depression (Abbasi et al., 2013). Fifteen percent to $25 \%$ of patients with depression have suicidal thoughts and sadism (Harati et al., 2014).

Different factors including biological, inherited, and psychosocial contribute to the development of depression. Recently, internal stressors such as variations in serum levels of cholesterol, triglyceride, sugar, and coagulation factors have been reported to be involved in the development of depression (Babri et al., 2012). Currently, certain drugs including lithium salts, stimulants, tricyclic antidepressants, serotonin inhibitors, and monoamine oxidase inhibitors are used to treat depression (Kamalipour et al., 2008).

These drugs may work some weeks to some months after use. Depression symptoms and signs are fully treated in only $1 / 3$ of people and the recurrence risk persists. Besides that, they can cause several adverse effects such as sleepiness, dry mouth, constipation, and impotence.

Currently, researchers are seeking out more specific drugs with higher safety and lower cost. Medicinal plants have attracted the attention of the researchers working in this field because these plants have long been used to treat different diseases, including psychia- 
tric disorders, and cause fewer adverse effects than synthetic and chemical drugs (Richelson, 1994).

The aim of this article is to review the findings of the studies on antidepressant effects and mechanism of action of medicinal plants and the biological compounds of these plants responsible for the antidepressant action.

\section{Biomarkers to study depression}

Monoamine neurotransmitters such as serotonin (5HT), noradrenaline and dopamine play a significant part in mediating depressive behaviors. Depression symptoms develop mainly due to declined activity of these neurotransmitters. Monoamine oxidase (MAOA) is a key enzyme that is dependent on neurotransmitters metabolism. MAOA activity rate has been suggested to be one of the susceptibility indices of psychological trauma (Pan et al., 2005).

The function of hypothalamic-pituitary-adrenal (HPA) axis has been demonstrated to become defective in patients with depression. Corticotropin-releasing factor (CRF) is the main physiological regulator of HPA axis and contributes fundamentally to mediating behavioral, neuroendocrine, and autonomic responses to environmental stimuli. Increased amount of CRF and excessive activity of HPA axis are considered depression indices (Barden et al., 1995; Pan et al., 2007).

Excessive release of glucocorticoid hormones, such as corticosterone in mice and cortisol in humans, that are produced in response to stressful conditions, is also an indicator of HPA axis excessive activity and development of depression (Xu et al., 2008). Fluoxetine has been demonstrated to be able to decrease the escalated amounts of serum corticosterone in mice with depression (Song et al., 2006). The amounts of corticotropin releasing hormone $(\mathrm{CRH})$, cortisol, and adrenocorticotropin hormone $(\mathrm{ACTH})$ have been reported to be higher in people with depression than other people (Plotsky et al., 1998).

Adenylyl cyclase is a drug that regulates the physiological effects of drugs and hormones through producing cAMP. cAMP is a secondary messenger involved in depressant and antidepressant processes. Adenylyl cyclase activity has been demonstrated to be associated with major depressive disorder. First, the brain (Cowburn et al., 1994) but then the platelets of suicideattempting people with previous depression were used to study adenylyl cyclase activity in these people.

Adenylyl cyclase has been demonstrated to be less active in people with depression than other people (Menninger and Tabakoff, 1997). Therefore, adenylyl cyclase activity can be considered to be the biological index of depression (Li et al., 1999). Adenylyl cyclase activity is controlled by serotonergic system receptors; serotonergic system, HPA axis, and adenylyl cyclasecAMP pathway have been demonstrated to interact with each other due to chronic stress in rats with depression (Xu et al., 2008).

Oxidative stress, a type of imbalance between the production of reactive oxygen species and anti-oxidant defense system, is one of the factors involved in the pathogenesis of depression. Different degrees of oxidetive damage and a decline in anti-oxidant enzymes have been reported in people with depression (Pandya et al., 2013). Use of anti-oxidant compounds such as nacetyl cysteine causes decrease in depression symptoms in people with depression. Besides that, antidepressants are able to decrease some of the oxidative stress indices and cause an increase in certain internal anti-oxidants (Maes et al., 2011).

Evidence indicates that certain inflammatory mediators such as tumor necrosis factor (TNF)- $\alpha$ and interleukin (IL) $-1 \beta$ are involved in the development of depression in both affected people and animal models (Liu et al., 2015). In a study, administration with IL-6, IL-1 $\beta$, TNF$a$, and lipopolysaccharides caused induction of depression- and anxiety-associated behaviors (Sukoff Rizzo et al., 2012).

As well, depression symptoms are seen in people with hepatitis $\mathrm{C}$ or cancer who are under immunotherapy with IL-2 and TNF-y. This confirms an association between inflammation and depression (Dutcher et al., 2000). Certain antidepressants such as fluoxetine and paroxetine are able to reduce inflammatory cytokines in the brain and blood (Hwang et al., 2008).

Disturbed metabolism of energy, amino acids, intestinal microflora, and amino acid neurotransmitters are associated with depression, which can be inferred from significant variations in their biomarkers (Xing et al., 2015). Creatinine and succinic acid play role in energy transport and creeps cycle whose inefficiency due to depression leads to disturbed energy metabolism and feeling tired, a main symptom of depression. Phenylalanine is an essential amino acid that acts as a precursor of tyrosine. Certain monoamine neurotransmitters including serotonin, norepinephrine, and epinephrine are derived from phenylalanine. Tryptophan is an essential amino acid and the precursor of serotonin. Therefore, the variations in tyrosine, tryptophan, and phenylalanine that represent disturbed metabolism of amino acids are associated with depression.

Hippuric acid is one of the phenylalanine metabolites that is metabolized by intestinal microflora. 3-Indoleacetic acid is produced by intestinal microflora-induced changes in tryptophan. Depression-induced variations in these biomarkers may represent an association between depression and intestinal microflora 
metabolism (Ladep et al., 2006). Glutamic acid and amino butyric acid (GABA) serve as stimulatory and inhibitory neurotrans-mitters in mammalian brain and contribute significantly to mediating anxiety- and depression-associated behaviors (Zheng et al., 2010).

An experimental study demonstrated that the amounts of tryptophan, phenyl, tyrosine, creatinine, succinic acid, 3-indoleacetic acid, and hippuric acid were lower in mice with depression than control mice, and use of a traditional Chinese medicinal plant, Zhi-Zi-Hou-Po, caused the amounts of these factors to reach normal levels. This medicinal plant also decreased the levels of glutamic acid and amino butyric acid to baseline levels (Xing et al., 2015).

Medicinal plants have been used to treat depression for thousands of years. Some of them include poppy (opium), deadly nightshade (Atropa belladonna), Indian hemp (hashish), henbane (hyoscyamine), thorn apple (scopolamine), and St. John's wort (hypericum oil). Opium poppy is widely cultivated and used by the Sumerians of the third millennium BC. Opium, the congealed latex from unripe poppy capsules, was also used in Minoan culture during the Bronze Age in the 3 rd and 2nd millennium BC. Atropa belladonna from the deadly nightshade and hashish from Indian hemp were used and cultivated as early as the third millennium BC in Egypt and Assyria. Hyoscyamine (a psychotropic alkaloids from henbane) and scopolamine (from thorn apple) are mentioned in the famous Ebers Papyrus (Egypt, 1500 BC) (Ban, 2001).

\section{Medicinal Plants}

\section{Danggui-Shaoyao-San}

Danggui-Shaoyao-San is a traditional Chinese medicinal plant routinely used in Asian countries. This herb contains six plants, Radix Angelicae sinensis, Poria cocos, Rhizoma Alisma orientalis, Radix Paeonia lactiflora, and Rhizoma Ligusticum chuanxiong, and is routinely used to treat gynecological disorders such as painful menstrual periods and postmenopausal problems.

Danggui-Shaoyao-San causes improvement of memory and learning impairment through preventing destruction of nerve cells and oxidative stress, decreasing and preventing accumulation of amyloid beta plaques, increasing synaptic plasticity, and reinforcing long-term potentiation ( $\mathrm{Hu}$ et al., 2012). The analgesic effects of this plant-based combination have been demonstrated, as well (Li et al., 2014). In a study, Danggui-ShaoyaoSan was found to exert therapeutic effects on chronic stress-induced depression. In addition, this remedy was effective in treating certain depression-associated symptoms such as weight loss, anorexia, investigative and locomotive activities, and insomnia (Zhou et al.,
2015).

Chronic stress causes sleep disorders by affecting certain neurotransmitters such as dopamine, serotonin, and norepinephrine that exert regulatory effects on sleep-wake cycle. A study showed that DangguiShaoyao-San caused an increase in monoamine neurotransmitters in the brain of elderly mice (Kou et al., 2005). A study on the antidepressant mechanism of Danggui-Shaoyao-San demonstrated that this remedy caused adjustment of noradrenaline and dopamine levels that were already decreased due to chronic stress as well as a decrease in malondialdehyde (MDA), and increase in superoxide dismutase (Huang et al., 2012).

The observed antidepressant effects of DangguiShaoyao-San can be related to the main compounds identified in this plant including albiflorin, paeonflorin, fluoric acid, ligustrazine, ligustilide and ateraacetyllinoid. Fluoric acid is a phenolic compound and contributes to treating and preventing a variety of diseases and disorders. Its sodium salt has been approved by the China Food and Drug Administration to treat cerebrovascular and cardiovascular diseases (Zhou et al., 2015).

Fruolic acid induces antidepressant effects through affecting serotonergic system (Zeni et al., 2012). Paeonflorin, another main compound of Danggui-ShaoyaoSan, caused the release of serotonin and norepinephrine from synaptosome and hence induction of anti-stress actions (Qiu et al., 2013).

Six medicinal materials were mixed in proportion and were macerated for 1 hour with eight volumes of distilled water and then decocted for 1.5 hours. Next, the cooled extract was filtered. The extraction procedure was repeated twice. The extracted fractions were pooled and concentrated using a rotary evaporator (Huang et al., 2012).

\section{Epimedium brevicornum}

In traditional Chinese medicine, E. brevicornum is used to reinforce kidneys and enhance the body's forces. This plant has a wide-spectrum of biological and pharmacological actions and contributes to regulating cardiovascular system, circulation, and reproductive system. E. brevicornum can exert estrogenic effects and is used to treat menopause symptoms (Pan et al., 2005). A number of studies have confirmed the antidepressant effects of E. brevicornum extract (Lai, 2001; Zhong et al., 2005). E. brevicornum extract seems to induce antidepressant effect through suppressing MAOA and monoamine oxidase $\mathrm{B}(\mathrm{MAOB})$ and reducing serum MDA (Zhong et al., 2005).

The flavonoids extracted from E. brevicornum increase certain neurotransmitters such as 5-HT and 5-HIAA, and gene expression of neurotransmitters receptors in 
the pituitary (Shen et al., 2004). The main compound of this plant, i.e. icarine (Figure 1), is a flavonoid compound and able to pass freely through the bloodbrain barrier and reduce brain inflammation and oxidative damage (Liu et al., 2015). Chronic stress caused physiological variations such as reduced sucrose preference and increased immobility (Liu et al., 2015).

In addition, chronic stress increases oxidative stress markers and inflammatory mediators such as TNF- $a$ and IL-1 $\beta$ and causes activation of nuclear factor $K$ messenger pathway and expression of nitric oxide synthase mRNA. Treatment with $20-40 \mathrm{mg} / \mathrm{kg}$ icarine caused decrease in oxidative stress markers and inflammatory mediators in the brain and significantly decreased depression symptoms in mice (Liu et al., 2015).

A study investigated the therapeutic effects of $E$. brevicornum-isolated icarine on chronic stress-induced depression. In this study, chronic stress was found to increase CRF and decrease serum triyedothyroine $\left(\mathrm{T}_{3}\right)$, but caused no significant variations in ACTH and thyroxine (T4). Subsequent treatment with icarine improved depression symptoms and decreased already escalated levels of CRF in the brain and serum in mice. Antidepressant effects of icarine can be due to adjustment of HTP HPA axis (Pan et al., 2007).

\section{Chrystactinia mexicana}

C. mexicana is widely used in North America, Mexico, and some South American countries to treat diseases. According to Mexican traditional medicine, C. mexicana is used to treat fever and rheumatism and as diuretic, sexual enhancer, anticonvulsant, stimulant, and tonic (Cassani et al., 2015). Cassani et al investigated the antidepressant effects of aqueous C. mexicana extract in mice using forced swim test and tail suspension test, and found this extract's antidepressant effects to be similar to those of a conventional antidepressant, clomipramine (Cassani et al., 2015).

The main compounds detected in aqueous C. mexicana extract are apigenin (Figure 1), caffeic acid, fruolic acid, and coumaric acid. The observed antidepressant effects for C. mexicana can be due to phenylpropanoids including caffeic acid, coumaric acid and fruolic acid (Cassani et al., 2015). The antidepressant effects of fruolic acid and caffeic acid have already been demonstrated (Zeni et al., 2012). Fruolic acid has antioxidant and anti-inflammatory effects and appears to be effective in treating neurodegenerative diseases (An et al., 2015).

Fruolic acid acts as NMDA receptor antagonist and protects nerve cells against NMDA excitotoxic effects (Yu et al., 2006). In addition, fruolic acid affects nerve cell cycle and causes an increase in neural stem cell division in vivo and in vitro (Yabe et al., 2010). Apigenin is a flavonoid compound that is found in most plants with sedative, anti-anxiety, and antidepressant properties. In vivo antidepressant effects of C. mexicana have been demonstrated. Apigenin exerts pharmacological effects by binding to the benzodiazepine binding site in $\mathrm{GABA}_{\mathrm{A}}$ receptors (Avallone et al., 2000).

The aerial parts of C. mexicana were air-dried and finely ground; afterward, aqueous extract was prepared at a ratio of $10 \mathrm{~g}$ of vegetal material per $90 \mathrm{~mL}$ of boiling distilled water and heated over $10 \mathrm{~min}$. The resulting extract was allowed to cool at room temperature, filtered, and dried in a freezer dryer Telstar, at $-50^{\circ} \mathrm{C}$ and $0.01 \mathrm{mBar}$, yielding $17.6 \%$ (1.76 g) of dried aqueous extract.

\section{Chamaemelun nobile}

C. nobile, chamomile in English language and Babouneh in Persian language, is from Asteraceae/Compositae family. This plant is native to different Mediterranean regions but now-a-days, exhibits a wide pattern of distribution in Europe and temperate areas of Asia and even the Americas. Diuretic, perspiratory, gastrotonic, carminative, stomachic, digestive, anti-inflammatory, antispasmodic, soothing, and antibacterial properties have already been reported for C. nobile (Jäger and Saaby, 2011). An experimental study demonstrated antidepressant effects of $C$. nobile extract on progesterone-induced major depressive disorder.

Although C. nobile extract decreased postpartum depression indices significantly in rats, it exerted no effect on oxidative stress indices. C. nobile antidepressant effects

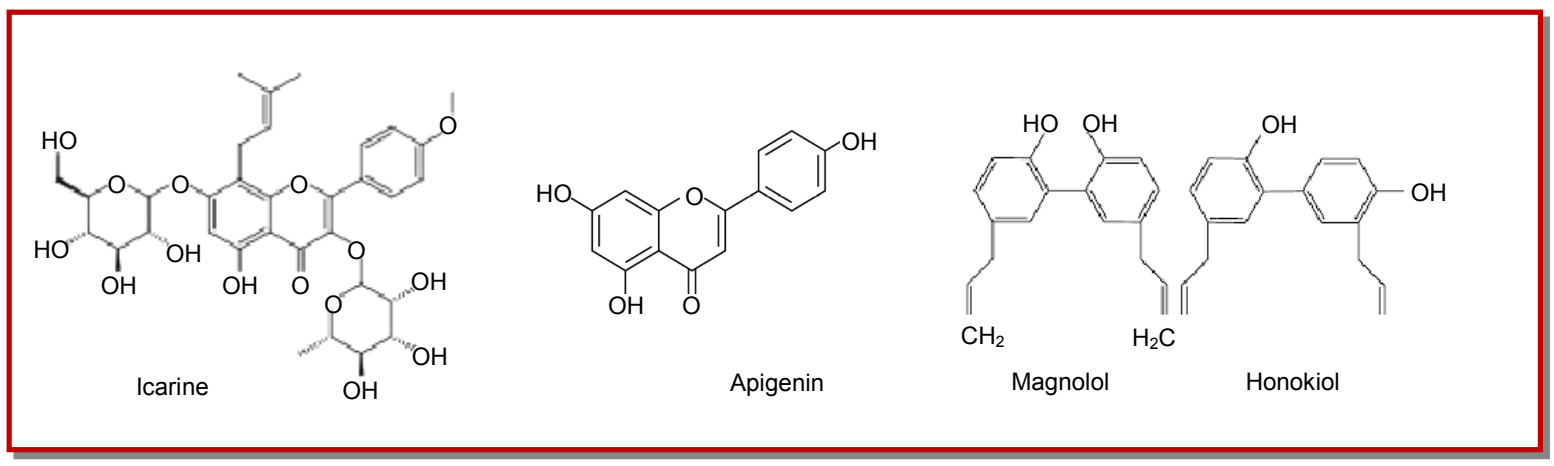

Figure 1: Chemical structure of icarine, apigenin, magnolol and honokiol 
can be related to the compounds of this plant (Harati et al., 2014). Certain flavonoids such as apigenin, quercetin, luteolin, and a terpenoid called a-bisabolol are the main active chemical elements found in C. nobile.

Apigenin, found in C. nobile, serves as a ligand for benzodiazepine receptor and hence has anti-anxiety and sedative properties, and significantly decreases delay in falling asleep. In contrast to diazepam, apigenin caused no impairment of memory (Jserves as a ligand). Another main compound of C. nobileis, quercetin which has been reported to induce inhibition of monoamine oxidase and hence sedative effects (Saaby et al., 2009).

\section{Magnolia officinalis}

Magnolia officinalis, M. dealbata, M. obovata, and $M$. grandiflora are the plants from family Magnoliacea which are used to treat neurological diseases such as convulsion, seizure, depression, and anxiety and as sedative and painkiller ( $\mathrm{Xu}$ et al., 2008; Chen et al., 2011). These plants are the main constituents of the herbal drugs used in Japan and China such as Banxiahoupu and Saiboku-to (Nakazawa et al., 2003).

Magnolol and honokiol (Figure 1) are two main compounds identified in these plants. These compounds have been reported to cause antidepressant effects through affecting serotonergic system (Kuribara et al., 1998). Xu et al (2008) investigated the effect of the oral use of these two compounds on mild chronic stressinduced depression. Mild chronic stress caused decrease in 5-HT and its metabolite, 5-HIAA, in different regions of the brain and suppressed the activity of platelets adenylyl cyclase. Serum corticesterone decreased due to chronic stress-induced depression, as well. Oral use of magnolol and honokiol (20 and $40 \mathrm{mg} / \mathrm{kg}$ ) caused a decrease in duration of immobility in forced swim test and increased sucrose preference.

These two compounds caused the changed amounts of 5-HT, 5-HIAA, corticosterone, and adenylyl cyclase to return to baseline levels. The antidepressant effects of magnolol and honokiol in this study were attributed to the repair of the induced disturbance in serotonergic system, HPA axis, and AC-cAMP pathway ( $\mathrm{Xu}$ et al., 2008).

\section{Hypericum perforatum}

H. perforatum, St John's wort in English language, is native to Europe but exhibits spontaneous distribution across the world particularly in temperate and subtropical regions including China, Turkey, Ukraine, Russia, India, Canada and the USA (Butterweck and Schmidt, 2007). To date, several studies have been conducted on antidepressant effects of $H$. perforatum in mice and humans that confirmed the potential therapeutic effects of this plant (Butterweck and Schmidt,
2007; Carpenter et al., 2008; Linde et al., 2008). $H$. perforatum extract contributes to not only treating depression but also preventing its recurrence. $H$. perforatum has a longer duration of response than citalopram (Singer et al., 2011).

In the recent years, $H$. perforatum has been competing for being commercially available as an antidepressant and for this reason several studies have been conducted to detect the chemical compounds responsible for this effect and their action mechanisms (Butterweck, 2003). Biochemical investigations have demonstrated that $H$. perforatum is a weak inhibitor of monoamine oxidase but inhibits synaptosomal resorption of serotonin, dopamine, and norepinephrine. $H$. perforatum extract exerts down-regulatory effect on beta-adrenergic receptors and up-regulatory effect on serotonin receptors, and changes the neurotransmitters concentrations in certain regions of the brain (Butterweck, 2003).

Moreover, methanolic $H$. perforatum extract causes expression of HPA axis-controlling genes (Butterweck et al., 2001). A study showed that $150-75 \mathrm{mg} / \mathrm{kg}$ of $H$. perforatum extract improved chronic stress-induced depression symptoms and decreased the escalated levels of serum ACTH and corticosterone (Grundmann et al., 2010). This extract also caused reinforcement of anti-oxidant defense system and decline in two inflammatory factors, IL-6 and TNF-a.

H. perforatum antidepressant effect was attributed to anti-oxidant, anti-inflammatory, and endocrine systemregulatory effects of this plant (Grundmann et al., 2010). The antidepressant effects of $H$. perforatum certain compounds such as hypericin, hyperforin, and isoquercetin have been demonstrated (Butterweck, 2003). Injection with hypericin caused $\mathrm{CRH}$ and expression of its related mRNA to decrease in mice with depression (Butterweck, 2003).

The aboveground parts (leaves, flowers and stem) were dried before extraction with $80 \%$ ethanol (vol/vol). The herb-to-extract ratio is $12: 1$ for a $100 \%$ native extract.

\section{Lavandula officinalis}

Lavandula genus, from family Lamiaceae, has 39 various species and exhibits a global distribution. Lavandula has certain properties such as gastrotonic, diuretic, perspiratory, anticonvulsant, carminative, antiheadache, nerve tonic, sedative, insomnia-treating, antianxiety, and anti-Alzheimer's disease (Harati et al., 2014). Antidepressant effects of a number of Lavandula species have been investigated. Hydroalcoholic and aqueous L. officinalis extracts $(100-400 \mathrm{mg} / \mathrm{kg})$, as with fluoxetine, exerted antidepressant effects in mice and significantly decreased immobility duration in forced swim test and tail suspension test (Harati et al., 2014). Inhaled L. officinalis extract caused an increase in plasma levels of serotonin and its metabolites in 
pregnant women at delivery (Mirzaei et al., 2009).

In a single-blind, controlled, random clinical trial, daily bathing with $L$. angustifolia essential oil caused improvement of mood and a significant decrease in depression symptoms (Akhondzadeh et al., 2003). Antidepressant properties of linalool, the main compound of L. angustifolia essential oil and extract, have been demonstrated. A study used pretreatment with WAY100635 (receptor antagonist 5-HT1A), PCPA (serotonin synthesis inhibitor), yohimbine (receptor antagonist $\alpha_{2}$ ), propranolol (receptor antagonist $\alpha \beta$ ), and DSP-4 (noradrenergic neurotoxin) to investigate linalool effect on serotonergic and noradrenergic systems in mice. In addition, injection with SCH23390 dopaminergic antagonist was used to investigate linalool effect on dopaminergic system in the mice.

Pretreatment with WAY100635 and yohimbine inhibited the antidepressant effects of linalool but other compounds had no effects on linalool antidepressant activity (Guzmán-Gutiérrez, 2015). Linalool's antidepressant effects can be exerted through receptors of serotonergic and noradrenergic systems.

Stems and flowers of L. officinalis were successively extracted with methanol by maceration at room temperature $\left(25^{\circ} \mathrm{C}\right)$ over a period of 48 hours. $500 \mathrm{~g}$ of plant material and one liter of methanol were used in the extraction. Methanol containing the extract was then filtered through Whatman paper and the solvent was vacuum distilled at $65^{\circ} \mathrm{C}$ in a rotary evaporator. The remaining extract was finally dried in the oven at $30^{\circ} \mathrm{C}$ for two hours to ensure the removal of any residual solvent (lyophilisation).

\section{Salvia sclarea}

Salvia is considered the most important genus from family Lamiaceae. Antidepressant effects of a number of the species from this genus have been confirmed. An experimental study showed that antidepressant effect of S. sclarea was more marked than those of Rosmarinus officinalis, L. angustifolia, and Anthemis nobilis. To determine antidepressant actions mechanisms of $S$. sclarea, pretreatment with antagonist or agonist receptors of serotonin, dopamine, adrenaline, and GABA was used. The antidepressant effect of S. sclarea was inhibited by buspirone (serotonin antagonist), $\mathrm{SCH}$ -23390 ( $\mathrm{aD}_{1}$ receptor antagonist), and haloperidol (antagonist receptors $\mathrm{D}_{2}, \mathrm{D}_{3}$ and $\mathrm{D}_{4}$ or dopamine receptor)

Therefore, it can be argued that antidepressant effect of $S$. sclarea is exerted through the dopaminergic system (Seol et al., 2010). Another study demonstrated that injection with hydroalcoholic extract of $S$. elegans caused relief of depression and anxiety in mice (Herrera -Ruiz et al., 2006). Antidepressant effects of a number of chemical compounds found in the plants from salvia genus, such as linalool and apigenin, have been confirmed (Avallone et al., 2000)

The leaves and flowers of Salvia were extracted in $60 \%$ ethanol solution at $50^{\circ} \mathrm{C}$ for 2 hours. Afterward, the extract was filtered through a Wattman \#1 paper and extracted once again (under the same conditions) with a new solvent. The obtained extracts were reunited and the solvent was evaporated to dryness with a rotary evaporator under reduced pressure (Seol et al., 2010).

\section{Rosmarinus officinalis $L$.}

R. officinalis is from family Labiatae and has numerous pharmacological effects including hepatoprotective, antibacterial, antiulcer, anticoagulant, diuretic, antidiabetic, anti-oxidant, and anti-inflammatory (Machado et al., 2013). An experimental study showed that treatment with hydroalcoholic $R$. officinalis extract $(100 \mathrm{mg} / \mathrm{kg})$ significantly decreased immobility duration in forced swim test and suspension in mice. Pretreatment with $\mathrm{p}$ chlorophenylalanine (serotonin synthesis inhibitor), NAN-190 (receptor antagonist 5- $\mathrm{HT}_{1 \mathrm{~A}}$ ), ketanserin (receptor antagonist 5- $\mathrm{HT}_{2 \mathrm{~A}}$ ), $\mathrm{mCPBG}$ (antagonist receptor 5- $\left.\mathrm{HT}_{3}\right)$, prazosin $\left(\mathrm{a}_{1}\right.$ adrenoreceptor antagonist), SCH23390 ( $\mathrm{D}_{1}$ dopamine receptor antagonist), and sulpiride ( $\mathrm{D}_{2}$ dopamine receptor antagonist) inhibited the antidepressant effects of $R$. officinalis extract.

Pretreatment with yohimbine ( $\mathrm{a}_{2}$ adrenoreceptor antagonist) had no contribution to the extract's antidepressant effects. Indeed, antidepressant effects of $R$. officinalis extract may be exerted through monoaminergic system (Machado et al., 2009).

The effects of $R$. officinalis polyphenols, consisting of carnosic acid, rosmarinic acid, and luteolin, on depression and PC12 cells, as an in vitro neurological model, were studied in mice. Proteomic analysis of PC12 cells demonstrated that $R$. officinalis caused upregulation of tyrosine hydroxylase and pyruvate carboxylase (the genes involved in gabaergic, serotonergic and dopaminergic systems). R. officinalis polyphenols also protected nerve cells against corticosterone -induced toxicity (Sasaki et al., 2013).

Another main compound of $R$. officinalis, ursolic acid, at $0.1 \mathrm{mg} / \mathrm{kg}$ exerted an antidepressant effect in mice, that were reinforced in the presence of dopamine receptor agonists and inhibited in the presence of dopamine receptor antagonists (Machado et al., 2012).

Dried aerial parts of R. officinalis (600 g), was submitted to maceration in ethanol (96\%) during 15 days at room temperature $\left(25 \pm 2{ }^{\circ} \mathrm{C}\right)$. Thereafter, the extract was filtered and then concentrated under reduced pressure (at approximately $60^{\circ}$ ). The maceration was repeated three times. After removing the solvent by liophylization, this procedure gave $61 \mathrm{~g}$ of a green solid 
and dry ethanolic crude extract (Machado et al., 2009).

\section{Schinus molle}

S. molle, from family Anacardiaceae, is native to South America but has been introduced to most tropical and subtropical regions across the world. This plant has been reported to exert certain pharmacological properties including anti-inflammatory, antitumor, antifungal, anticonvulsant, and analgesic (Machado et al., 2007). Injection with $n$-hexane $S$. molle extract (3-600 mg/ kg) significantly decreased the immobility duration in tail suspension test in mice with an efficacy comparable to that of fluoxetine $(10 \mathrm{mg} / \mathrm{kg})$.

Pretreatment with p-chlorophenylalanine methyl ester (serotonin synthesis inhibitor), NAN-190 (5-HT $1 \mathrm{~A}$ receptor antagonist), WAY100635 $\left(5-\mathrm{HT}_{1 \mathrm{~A}}\right.$ receptor antagonist of choice), prazosin ( $\alpha_{1}$ adrenoreceptor antagonist), ketanserin $\left(5-\mathrm{HT}_{2 \mathrm{~A} / 2 \mathrm{C}}\right.$ receptor antagonist of choice), MDL72222 (5- $\mathrm{HT}_{3}$ receptor antagonist of choice), yohimbine ( $\alpha_{2}$ adrenoreceptor antagonist), $\mathrm{SCH} 23390$ ( $\mathrm{D}_{1}$ dopamine receptor antagonist), and sulpiride $\left(\mathrm{D}_{2}\right.$ dopamine receptor antagonist) inhibited S. molle-induced antidepressant effects. Antidepressant effects of $n$-hexane $S$. molle extract can be exerted through serotonergic, dopaminergic and noradrenergic systems.

Rutin, a flavonoid compound isolated from $S$. molle, at 0.3-3 $\mathrm{mg} / \mathrm{kg}$ concentrations exerted an antidepressant effect in mice, which was inhibited in the presence of $\mathrm{p}$ chlorophenylalanine methyl ester (serotonin synthesis inhibitor) and a-methyl-p-tyrosine (noradrenaline synthesis inhibitor). Rutin induces antidepressant effects probably through increasing noradrenaline and serotonin in the synaptic gap (Machado et al., 2008).

Dried sample was extracted with $n$-hexane at room temperature $\left(25 \pm 2^{\circ} \mathrm{C}\right)$ for 15 days. Thereafter, the extract was filtered and then concentrated under reduced pressure (at approximately $60^{\circ}$ ). The maceration was repeated three times. The evaporation of solvent yielded a residue of $17.8 \mathrm{~g}$ of dried extract $(4.6 \% \mathrm{w} / \mathrm{w}$ yield). The remaining residue was kept in a refrigerator and dissolved in saline with $10 \%$ Tween 80 before the behavioral tests (Machado et al., 2008).

\section{Discussion}

A variety of chemical and synthetic drugs are available to treat depression, but most of the patients fail to tolerate the adverse effects due to these drugs. Moreover, only $50 \%$ of the patients experience a complete recovery. Currently, studies are being increasingly conducted to detect new and economical drugs to treat depression with no adverse effects (Saki et al., 2014). Meanwhile, medicinal plants have been reported to exert pharmacologically optimal effects in treating depression in different animal models (Herrera -Ruiz, Garccinal plants have been). Forced swim test and tail suspension test are animal pharmacological models commonly used to investigate antidepressant effects of chemical compounds and different plants in rodents (mostly mice). In addition to the abovementioned plants, certain plants such as Apocynum venetum, Zingiber officinale Roscoe, Tagetes lucida Cav, Eugenia brasiliensis Lam, Hedyosmum brasiliense, Crocus satious, Bupleurum Falcaria, Scrophularia striata, Panax notoginseng, and Piper methysticum have been reported to exert antidepressant effects (Lehmann et al., 1996; Butterweck et al., 2001; Akhondzadeh et al., 2005; Guadarrama-Cruz et al., 2008; Kwon et al., 2010; Tolardo et al., 2010; Babri et al., 2012; Colla et al., 2012; Yao et al., 2012; Farzin et al., 2013).

In the light of the above-mentioned, most of the medicinal plants and their active compounds reported in this review article were found to exert therapeutic effects through interactions with serotonergic $\left(5-5 \mathrm{HT}_{3}, 5-\right.$ $5 \mathrm{HT}_{2} \mathrm{~A}$, and $\left.5 \mathrm{HT}_{1 \mathrm{~A}}\right)$, noradrenergic ( $\mathrm{a}_{1}$ and $\mathrm{a}_{2}$ receptors), and dopaminergic ( $\mathrm{D}_{1}$ and $\mathrm{D}_{2}$ receptors) systems. In addition, medicinal plants cause regulation of HPA axis activity and decrease in the increased amounts of corticotropin, $\mathrm{CRH}, \mathrm{ACTH}$ and $\mathrm{CRH}$.

Oxidative stress is one of the factors involved in depression pathophysiology, and different degrees of oxidative stress and a decrease in anti-oxidant enzymes have been reported in people with depression (Pandey et al., 1992). Evidence indicates that the levels of certain inflammatory mediators are higher in people with depression than other people (Liu et al., 2015). Some medicinal plants such as Danggui-Shaoyao-San and E. brevicornum exert antidepressant effects through reducing oxidative stress and inflammatory mediators (Zheng et al., 2010; Liu et al., 2015).

A review of the findings on medicinal plants' antidepressant effects indicates that most research has been conducted on animal models and few plants including $H$. perforatum and $L$. officinalis have been investigated for antidepressant effects in humans. Given that the chemical compounds of the plants are metabolized through enzymatic processes of the body and liver and for this reason their structure and actions are likely to vary, it is recommended to conduct clinical trials in addition to preclinical studies (Yao et al., 2012).

In most studies on antidepressant effects of medicinal plants, their toxicity and the margin of safety between therapeutic and toxic effects were not investigated. Cassani et al study reported no mortality due to oral use of C. mexicana up to $5,000 \mathrm{mg} / \mathrm{kg}$ concentration in rats. The active concentration to treat depression was seven times larger than $\mathrm{LD}_{50}$, which confirms the safety of this concentration. The body's weight and organs' relative weights are among the indices investigated in 
toxicological studies. These indices did not decrease due to the use of $C$. mexicana extract with no injuries or pathological variations in vital organs (Cassani et al., 2015). Therefore, the toxic effects of medicinal plants and their active compounds are recommended to be studied to confirm the safety of use.

Recently, promising evidence has been reported on the medicinal plants' effects in treating or preventing different diseases including impairments of memory (Baradaran et al., 2012; Rabiei et al., 2013; Alibabaei et al., 2014; Mokhtari-Dehkordi et al., 2014; Rabiei et al., 2014; Rabiei et al., 2014; Rabiei et al., 2014; Rabiei and Rafieian, 2014; Rahnama et al., 2014) and different types of strokes (Rabiei et al., 2012; Rabiei et al., 2012; Rabiei et al., 2012; Rabiei et al., 2013; Rabiei and RafieianKopaei, 2014). Although these observations can be attributed to specific compounds of these plants, they have been attributed mainly to their anti-oxidant properties.

In the recent years, selling nature-based compounds to treat depression and anxiety has been considerably on rising and these compounds have been welcome by consumers. In Europe, H. perforatum is used as capsule and tablet (300 mg, taken twice a day) to treat depression, but the US Food and Drug Administration has not approved it to treat depression. 5-hydroxytryptophan, largely found in squash, turnip, cabbage, potato, sunflower seeds, and seaweed, is commercially available to treat depression. 5-hydroxytryptophan is able to improve depression symptoms through increasing serotonin. Besides that, antidepressant effects of saffron, L. officinalis, and P. methysticum have been confirmed in human subjects and are commercially available to treat depression.

\section{Acknowledgement}

This article was written by funding of the Research and Technology Deputy of the Shahrekord University of Medical Sciences.

\section{References}

Abbasi Maleki S, Bekhradi R, Asgharpanah J, Abbasi Maleki F and Maleki A. Antidepressant effect of aqueous and hydroalcoholic extracts of Lavandula officinalis in forced swim test and tail suspension test in male mice. J Arak Univ Med Sci. 2013; 16: 65-75.

Akhondzadeh S, Kashani L, Fotouhi A, Jarvandi S. Comparison of Lavandula angostofolia Mill. tincture and imipramine in the treatment of mild to moderate depression: A doubleblind, randomized pilot study. Prog Neuropsychopharmacol Biol Psychiatry. 2003; 27: 123-27.

Akhondzadeh S, Tamacebi-pour N, Noorbala A, Amini H, Fallah Pour H, Jamshidi A. Crocus sativus L. in the treatment of mild to moderate depression: A double-blind, randomized and placebo controlled trial. Phytotherapy Res. 2005; 19: 25-29.

Alibabaei Z, Rabiei Z, Rahnama S, Mokhtari S, Rafieian-kopaei M. Matricaria chamomilla extract demonstrates anti-oxidant properties against elevated rat brain oxidative status induced by amnestic dose of scopolamine. Biomed Aging Pathol. 2014; 4: 355-60.

An L, Li J, Yu ST, Xue R, Yu NJ, Chen HX. Effects of the total flavonoid extract of Xiaobuxin-Tangon depression-like behavior induced by lipopolysaccharide and proinflammatory cytokine levels in mice. J Ethnopharmacol. 2015; 163: 83-87.

Avallone R, Zanoli P, Puia G, Kleinschnitz M, Chreier P, Baraldi M. Pharmacological profile of apigenin, a flavonoid isolated from Matricaria chamomilla. Biochem Pharmacol. 2000; 59: 1387-94.

Babri S, Doosti M, Fatehi L, Salari A. The effects of Scrophularia striata extract on anxiety and depression behaviors in adult male mice. Pharm Sci. 2012; 18: 133-40.

Baradaran ARZ, Rafieian M, Shirzad H. A review study on medicinal plants affecting amnesia through cholinergic system. J Herb Med Pharmacol. 2012; 1: 3-9.

Barden N, Reul J, Holsboer F. Do antidepressants stabilize mood through actions on the hypothalamic-pituitaryadrenocortical system? Trends Neurosci. 1995; 18: 6-11.

Ban T. Pharmacotherapy of depression: A historical analysis. J Neural Transm . 2001; 108: 707-16.

Butterweck V. Mechanism of action of St John's wort in depression. CNS Drugs. 2003; 17: 539-62.

Butterweck V, Korte B, Winterhoff H. Pharmacological and endocrine effects of Hypericum perforatum and hypericin after repeated treatment. Pharmacopsychiatry 2001;34: 2-7.

Butterweck V, Schmidt M. St. John's wort: Role of active compounds for its mechanism of action and efficacy. Wien Med Wochenschr. 2007; 157: 356-61.

Carpenter C, Crigger N, Kugler R, Loya A. Hypericum and nurses: A comprehensive literature review on the efficacy of St. John's wort in the treatment of depression. J Holist Nurs. 2008; 26: 200-07.

Cassani J, Alberto Ferreyra-Cruz O, María Dorantes-Barrón A, Vigueras Villaseñor RM, Arrieta-Baez D, Estrada-Reyes R. Antidepressant-like and toxicological effects of a standardized aqueous extract of Chrysactinia mexicana A. Gray (Asteraceae) in mice. J Ethnopharmacol. 2015; 171: 295306.

Chen CR, Tan R, Qu WM, Wu Z, Wang Y, Urade Y, Huang ZL. Magnolol, a major bioactive constituent of the bark of Magnolia officinalis, exerts antiepileptic effects via the GABA/ benzodiazepine receptor complex in mice. Br J Pharmacol. 2011; 164: 1534-46.

Colla ARS, Machado DG, Bettio LEB, Colla G, Magina MDA, Brighente IMC. Involvement of monoaminergic systems in the antidepressant-like effect of Eugenia brasiliensis Lam. (Myrtaceae) in the tail suspension test in mice. J Ethnopharmacol. 2012; 143: 720-31.

Cowburn R, Marcusson J, Eriksson A, Wiehager B, O'Neill C. 
Adenylyl cyclase activity and G-protein subunit levels in postmortem frontal cortex of suicide victims. Brain Res. 1994; 633: 297-304.

Dutcher JP, Logan T, Gordon M, Sosman J, Weiss G, Margolin K, Plasse T, Mier J, Lotze M, Clark J, Atkins M. Phase II trial of interleukin 2, interferon alpha, and 5-fluorouracil in metastatic renal cell cancer: A cytokine working group study. Clin Cancer Res. 2000; 6: 3442-50.

Farzin D, Fathiaza F, Fazellian M. Antidepressant effect of methanolic ginger extract in diabetic mice using forced-swim test. J Mazand Univ Med Sci. 2013; 23: 208-20.

Grundmann O, Lva Y, Kelber O, Butterweck V. Mechanism of St. John's wort extract (STW3-VI) during chronic restraint stress is mediated by the interrelationship of the immune, oxidative defense, and neuroendocrine system. Neuropharmacol. 2010; 58: 767-73.

Guadarrama-Cruz G, Alarcon-Aguilar FJ, Lezama-Velasco R, Vazquez-Palacios G, Bonilla-Jaime H. Antidepressant-like effects of Tagetes lucida Cav. in the forced swimming test. J Ethnopharmacol. 2008; 120: 277-81.

Guzmán-Gutiérrez SL, Bonilla-Jaime H, Gómez-Cansino R, Reyes-Chilpa R. Linalool and $\beta$-pinene exert their antidepressant-like activity through the monoaminergic pathway. Life Sci. 2015; 128: 24-29.

Harati E, Roodsari HRS, Seifi B, Kamalinejad M, Nikseresht S. The effect of oral Matricaria chamomilla extract and selenium on postpartum depression and plasma oxidant-anti-oxidant system in mice. Tehran Univ Med J. 2014; 71: 625-34.

Herrera-Ruiz M, García-Beltrán Y, Mora S, Díaz-Véliz G, Viana GS, Tortoriello J, Ramírez G. Antidepressant and anxiolytic effects of hydroalcoholic extract from Salvia elegans. J Ethnopharmacol. 2006; 107: 53-58.

Hu Z, Liu G, Cheng X, Huang Y, Yang S, Qiao S. JD-30 an active fraction extracted from Danggui-Shaoyao-San decreases beta-amyloid content and deposition, improves LTP reduction and prevents spatial cognition impairment in SAMP8 mice. Exp Gerontol. 2012; 47: 14-22.

Huang Z, Mao QQ, Zhong XM, Li ZY, Qiu FM. Mechanistic study on the antidepressant-like effect of Danggui-ShaoyaoSan, a chinese herbal formula. Evid Based Complement Alternat Med. 2012; 12: 1-7.

Hwang J, Zheng LT, Ock J, Lee MG, Kim SH, Lee HW, Lee $\mathrm{WH}$, Park HC and Suk K. Inhibition of glial inflammatory activation and neurotoxicity by tricyclic antidepressants. Neuropharmacol 2008; 55: 826-34.

Jäger A, Saaby L. Flavonoids and the CNS. Molecules 2011; 16: 1471-85.

Kou J, Zhu D, Yan Y. Neuroprotective effects of the aqueous extract of the Chinese medicine Danggui-Shaoyao-San on aged mice. J Ethnopharmacol. 2005; 97: 313-18.

Kuribara H, Stavinoha W, Maruyama Y. Behavioural pharmacological characteristics of honokiol, an anxiolytic agent present in extracts of Magnolia bark, evaluated by an elevated plus-maze test in mice. J Pharm Pharmacol Biochem Behav. 1998; 50: 819-26.

Kwon S, Lee B, Kim M, Lee H, Park HJ, Hahm DH.
Antidepressant-like effect of the methanolic extract from Bupleurum falcatum in the tail suspension test. Prog Neuropsychopharmacol Biol Psychiatry. 2010; 34: 265-70.

Kamalipour M, Akhondzadeh S, Rezazadeh S. Herbal medicines in the treatment of depression and anxiety. J Med Plants. 2008; 7: 1-6.

Ladep NG, Obindo TJ, Audu MD, Okeke EN, Malu AO. Depression in patients with irritable bowel syndrome in Jos, Nigeria. World J Gastroenterol. 2006; 28: 7844-47.

Lai Z. Clinical application of Epimedium brevicornum. J Liaoning Coll Tradit Chin Med. 2001; 3: 266-73.

Lehmann E, Kinzler E, Friedemann J. Efficacy of a special kava extract (Piper methysticum) in patients with states of anxiety, tension and excitedness of non-mental origin: A doubleblind placebo-controlled study of four weeks treatment. Phytomedicine 1996; 3: 113-19.

Li H, Gu Z, Wu L, Xia L, Zhou K, Wang D, Kou J, Liu H. Danggui-Shaoyao-San, a traditional Chinese medicine prescription, alleviates the orthodontic pain and inhibits neuronal and microglia activation. Chin Med J. 2014; 127: 3630-37.

Li Y, Gong Z, Zhang H, Luo Z. Effect of antidepressants on adenylate cyclase activity of rat cerebral cortex. Bull Acad Military Med Sci. 1999; 2: 18.

Linde K, Berner M, Kriston L. St John's wort for major depression. Cochrane Database Syst Rev. 2008; 8: 5-9.

Liu B, Xu C, Wu X, Liu F, Du Y, Sun J, Tao J, Dong J. Icariin exerts an antidepressant effect in an unpredictable chronic mild stress model of depression in rats and is associated with the regulation of hippocampal neuroinflammation. Neuroscience 2015; 294: 193-205.

Machado DG, Neis VB, Balen GO, Colla A, Cunha MP, Dalmarco JB. Antidepressant-like effect of ursolic acid isolated from Rosmarinus officinalis L. in mice: Evidence for the involvement of the dopaminergic system. Pharmacol Biochem Behav. 2012; 103: 204-11.

Machado DG, Kaster MP, Binfaré RW, Dias M, Santos ARS, Pizzolatti MG. Antidepressant-like effect of the extract from leaves of Schinus molle L. in mice: Evidence for the involvement of the monoaminergic system. Prog Neuropsychopharmacol Biol Psychiatry. 2007; 31: 421-28.

Machado DG, Bettio LEB, Cunha MP, Santos ARS, Pizzolatti MG, Brighente IMC. Antidepressant-like effect of rutin isolated from the ethanolic extract from Schinus molle L. in mice: Evidence for the involvement of the serotonergic and noradrenergic systems. Eur J Pharmacol. 2008; 587: 163-68.

Machado DG, Bettio LE, Cunha MP, Capra JC, Dalmarco JB, Pizzolatti MG, Rodrigues AL. Antidepressant-like effect of the extract of Rosmarinus officinalis in mice: Involvement of the monoaminergic system. Neuropsychopharmacol Biol Psychiatry. 2009; 33: 642-50.

Machado DG, Cunha MP, Neis VB, Balen GO, Colla A, Bettio LE, Oliveira A, Pazini FL, Dalmarco JB, Simionatto EL, Pizzolatti MG, Rodrigues AL. Antidepressant-like effects of fractions, essential oil, carnosol and betulinic acid isolated from Rosmarinus officinalis L. Food Chem. 2013; 136: 9991005. 
Maes M, Galecki P, Chang Y, Berk M. A review on the oxidative and nitrosative stress (O \& NS) pathways in major depression and their possible contribution to the (neuro) degenerative processes in that illness. Prog Neuropsychopharmacol Biol Psychiatry. 2011; 35: 676-92.

Menken M, Munsat T, Toole J. The global burden of disease study: Implications for neurology. Arch Neurol. 2000; 57: 418 -20 .

Menninger J, Tabakoff B. Forskolin-stimulated platelet adenylyl cyclase activity is lower in persons with major depression. Biol Psychiatry. 1997; 42: 30-38.

Mirzaei F, Keshtgar S, Kaviani M, Rajaeifard A. The effect of lavender ssence smelling during labor on cortisol and serotonin plasma levels and anxiety reduction in nulliparous women. J Kerman Univ Med Sci. 2009; 16: 245-54.

Mokhtari-Dehkordi S, Rouhi L, Rabiei Z. Effect of ethanolic extract of beet roots and leaves on motor coordination in male Wistar rats. J Shahrekord Univ Med Sci. 2014; 16: 10815.

Nakazawa T, Yasuda T, Ohsawa K. Metabolites of orally administered Magnolia officinalis extract in rats and man and its antidepressant-like effects in mice. J Pharm Pharmacol. 2003; 55: 1583-91.

Pan Y, Kong LD, Li YC, Xia X, Kung HF, Jiang FX. Icariin from Epimedium brevicornum attenuates chronic mild stressinduced behavioral and neuroendocrinological alterations in male Wistar rats. Pharmacol Biochem Behav. 2007; 87: 13040.

Pan Y, Kong L, Xia X, Zhang W, Xia Z, Jiang F. Antidepressant -like effect of icariin and its possible mechanism in mice. Pharmacol Biochem Behav. 2005; 82: 686-94.

Pandey G, Sharma R, Janicak P, Davis J. Monoamine oxidase and cortisol response in depression and schizophrenia. Psychiatry Res. 1992; 44: 1-8.

Pandya C, Howell K, Pillai A. Anti-oxidants as potential therapeutics for neuropsychiatric disorders. Prog Neuropsychopharmacol Biol Psychiatry. 2013; 46: 214-23.

Plotsky PM, Owens MJ, Nemeroff CB. Psychoneuroendocrinology of depression: Hypothalamic-pituitary-adrenal axis. Psychiatr Clin North Am. 1998; 21: 293-307.

Qiu F, Zhong X, Mao Q, Huang Z. The antidepressant-like effects of paeoniflorin in mouse models. Exp Ther Med. 2013; 5: 1113-16.

Rabiei Z, Bigdeli M, Mohagheghi F, Rasolian B. Relationship between dietary virgin olive oil on brain cholesterol, cholesteryl ester and triglyceride levels and blood brain barrier (BBB) permeability in a rat stroke model. Physiol Pharmacol. 2012; 16: 245-54

Rabiei Z, Bigdeli MR, Rasoulian B. Neuroprotection of dietary virgin olive oil on brain lipidomics during stroke. Curr Neurovasc Res. 2013; 10: 231-37.

Rabiei Z, Bigdeli MR, Rasoulian B, Ghassempour A, Mirzajani $F$. The neuroprotection effect of pretreatment with olive leaf extract on brain lipidomics in rat stroke model. Phytomedicine 2012; 19: 940-46.
Rabiei Z, Bigdeli MR, Rasoulian B, Mohagheghi F, Sharifi A. The effect of various doses of olive leaf extract on brain lipid levels and blood brain barrier permeability in rat stroke model. Pajoohandeh J. 2012; 17: 67-72.

Rabiei Z, Gholami M, Hojjati M. The effect of Cyperus rotundus ethanolic extract on motor coordination in a rat model of alzheimer. ZUMS J. 2014; 22: 43-54.

Rabiei Z, Hojjati M, Rafieian-Kopaeia M, Alibabaei Z. Effect of cyperus rotundus tubers ethanolic extract on learning and memory in animal model of Alzheimer. Biomed Aging Pathol. 2013; 3: 185-91.

Rabiei Z, Rafieian-Kopaei M. Neuroprotective effect of pretreatment with Lavandula officinalis ethanolic extract on blood-brain barrier permeability in a rat stroke model. Asian Pac J Trop Med. 2014; 7: S421-26.

Rabiei Z, Rafieian-kopaei M, Heidarian E, Saghaei E, Mokhtari S. Effects of Zizyphus jujube extract on memory and learning impairment induced by bilateral electric lesions of the nucleus basalis of meynert in rat. Neurochem Res. 2014; 39: 353-60.

Rabiei Z, Rafieian-Kopaei M, Mokhtari S, Alibabaei Z, Shahrani M. The effect of pretreatment with different doses of Lavandula officinalis ethanolic extract on memory, learning and nociception. Biomed Aging Pathol. 2014; 4: 71-76.

Rabiei Z, Rafieian M. Effects of Zizyphus jujuba extract on motor coordination impairment induced by bilateral electric lesions of the nucleus basalis of meynert in rat. Physiol Pharmacol. 2014; 17: 469-77.

Rahnama S, Rabiei Z, Alibabaei Z, Mokhtari S, Rafieian-kopaei $\mathrm{M}$, Deris F. Anti-amnesic activity of citrus aurantium flowers extract against scopolamine-induced memory impairments in rats. Neurol Sci. 2014; 23: 1-8.

Richelson E. Pharmacology of antidepressants-characteristic of the ideal drug. Mayo Clin Proceed. 1994; 69: 1069-81.

Sukoff Rizzo SJ, Neal SJ, Hughes ZA, Beyna M, RosenzweigLipson S, Moss SJ, Brandon NJ. Evidence for sustained elevation of IL-6 in the CNS as a key contributor of depressive-like phenotypes. Transl Psychiatry. 2012; 2: 199208.

Saaby L, Rasmussen HB, Jager AK. MAO-A inhibitory activity of quercetin from Calluna vulgaris (L.) Hull J Ethnopharmacol. 2009; 121: 178-81.

Saki K, Bahmani M, Rafieian-Kopaei M. The effect of most important medicinal plants on two important psychiatric disorders (anxiety and depression): A review. Asian Pac J Trop Med. 2014; 7: 34-42.

Sasaki K, El Omri A, Kondo S, Han J, Isoda H. Rosmarinus officinalis polyphenols produce anti-depressant like effect through monoaminergic and cholinergic functions modulation. Behav Brain Res. 2013; 238: 86-94.

Seol GH, Shim HS, Kim PJ, Moon HK, Lee KH, Shim I, Suh SH, Min SS. Antidepressant-like effect of Salvia sclarea is explained by modulation of dopamine activities in rats. J Ethnopharmacol. 2010; 130: 187-90.

Shen Z, Chen Y, Huang J, Hu Z. The gene expression profile in 
hypothalamus-pituitary-adrenal-thymus (HPAT) axis from EF-treated old rats. Chin J Immunol. 2004; 20: 59-62.

Singer A, Schmidt M, Hauke W, Stade K. Duration of response after treatment of mild to moderate depression with Hypericum extract STW 3-VI, citalopram and placebo: A reanalysis of data from a controlled clinical trial. Phytomedicine 2011; 18: 739-42.

Song L, Che W, Wu M. Impairment of the spatial learning and memory induced by learned helplessness and chronic mild stress. Pharmacol Biochem Behav. 2006; 83: 186-93.

Tolardo R, Zetterman L, Bitencourtt DR, Mora TC, de Oliveira FL, Biavatti MW. Evaluation of behavioral and pharmacological effects of Hedyosmum brasiliense and isolated sesquiterpene lactones in rodents. J Ethnopharmacol. 2010; 128: 6370.

Xing H, Zhang K, Zhang R, Zhang Y, Gu L, Shi H, Bi K, Chen $X$. Determination of depression biomarkers in rat plasma by liquid chromatography-mass spectrometry for the study of the antidepressant effect of Zhi-Zi-Hou-Po decoction on rat model of chronic unpredictable mild stress. J Chromatogr B. 2015; 988: 135-42.

Xu Q, Yi LT, Pan Y, Wang X, Li YC, Li JM, Wang CP, Kong LD. Antidepressant-like effects of the mixture of honokiol and magnolol from the barks of Magnolia officinalis in stressed rodents. Prog Neuropsychopharmacol Biol Psychiatry. 2008; 32: $715-25$.
Yabe T, Hirahara H, Harada N, Ito N, Nagai T, Sanagi T, Yamada $H$. Ferulic acid induces neural progenitor cell proliferation in vitro and in vivo. Neuroscience 2010; 165: 515 -24 .

Yao Y, Sang W, Yang X, Zhai M, Wang L, Qin P, Wu LI, Zhou $X$, Wang L, Li J, Zhu Z. Antidepressant effects of ginsenosides from Panax notoginseng. J Integr Agr. 2012; 3: 483-88.

Yu L, Zhang Y, Ma R, Bao L, Fang J, Yu T. Potent protection of ferulic acid against excitotoxic effects of maternal intragastric administration of monosodium glutamate at a late stage of pregnancy on developing mouse fetal brain. Eur Neuropsychopharmacol. 2006; 16: 170-77.

Zeni AL, Zomkowski AD, Maraschin M, Rodrigues AL, Tasca CI. Ferulic acid exerts antidepressant-like effect in the tail suspension test in mice: Evidence for the involvement of the serotonergic system. Eur J Pharmacol. 2012; 679: 68-74.

Zheng S, Yu M, Lu X, Huo T, Ge L, Yang J, Wu C, Li F. Urinary metabonomic study on biochemical changes in chronic unpredictable mild stress model of depression. Clin Chim Acta. 2010; 411: 204-09.

Zhong HB, Pan Y, Kong LD. Antidepressant effect of Epimedium brevicornum extracts. CTHD. 2005; 10: 34-40.

Zhou K, Jia N, Jiang N, Wang F, Kou J. Beneficial effect of Danggui-Shaoyao-San, a traditional Chinese medicine, on drowsiness induced by chronic restraint stress. Neurosci Lett. 2015; 597: 26-31. 


\section{Your feedback about this paper}

1. Number of times you have read this paper 0

2. Quality of paper Click

3. Your comments

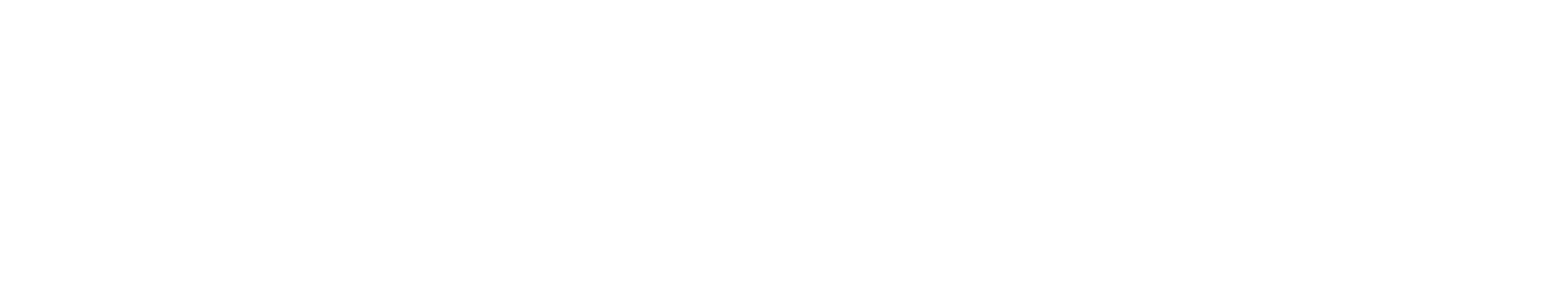

